\title{
Confinement of chiral molecules in reverse micelles: FT-IR, polarimetric and VCD investigation on the state of dimethyl tartrate in sodium bis(2-ethylhexyl) sulfosuccinate reverse micelles dispersed in carbon tetrachloride
}

\author{
Sergio Abbate ${ }^{\mathrm{a}}$, Giovanna Longhi ${ }^{\mathrm{a}}$, Angela Ruggirello ${ }^{\mathrm{b}}$, Vincenzo Turco Liveri ${ }^{\mathrm{b}, *}$ \\ a Dipartimento di Scienze Biomediche e Biotecnologie, Università di Brescia, Viale Europa 11, 25123 Brescia, Italy \\ b Dipartimento di Chimica Fisica, Università di Palermo, Viale delle Scienze, Parco d'Orleans II, 90128 Palermo, Italy
}

\section{A R T I C L E I N F O}

\section{Article history:}

Received 13 February 2008

Received in revised form 24 April 2008

Accepted 3 June 2008

Available online 8 June 2008

\section{Keywords:}

Dimethyl tartrate

Sodium bis(2-ethylhexyl) sulfosuccinate

Reverse micelles

Chiral nanostructures

FT-IR spectroscopy

Vibrational circular dichroism

Optical rotation

\begin{abstract}
A B S T R A C T
The state of $\mathrm{D}$ and L-dimethyl tartrate confined within dry sodium bis(2-ethylhexyl) sulfosuccinate (AOT) reverse micelles dispersed in $\mathrm{CCl}_{4}$ has been investigated by FT-IR spectroscopy, polarimetry, and vibrational circular dichroism (VCD). Measurements have been performed at $25^{\circ} \mathrm{C}$ as a function of the solubilizate-to-surfactant molar ratio $(R)$ at a fixed AOT concentration $(0.158 \mathrm{M})$. The analysis of experimental data is consistent with the hypothesis that both enantiomers of dimethyl tartrate are mainly entrapped in the reverse micelles and located in proximity to the surfactant head-group region. The formation of this interesting self-organized chiral nanostructure involves some changes of the typical $\mathrm{H}$-bonding of dimethyl tartrates in the pure solid state or as monomers dispersed in $\mathrm{CCl}_{4}$ attributable to the establishment of specific solubilizate/surfactant head-group interactions and confinement effects.
\end{abstract}

(c) 2008 Elsevier B.V. All rights reserved.

\section{Introduction}

It is well known that solutions of reverse micelles can solubilize many kinds of molecules. This is because these systems are characterized by the coexistence of a multiplicity of domains: the bulk apolar solvent, the so-called palisade layer constituted by the surfactant alkyl chains, the hydrophilic region formed by the surfactant polar head groups and the internal micellar core. Hydrophobic molecules are largely dispersed in the apolar medium and micellar palisade layer, ionic and polar substances are entrapped within the hydrophilic micellar core and/or among the surfactant head groups while amphiphilic solutes are partitioned between bulk solvent and reverse micelles where they are preferentially located, opportunely oriented, between the headgroup domain and the micellar palisade layer. However, the specific site of the solubilizate does not depend only from its nature but also from its size and shape as well as on the structural and dynamic properties of reverse micelles. In addition, type and surfactant concentration, nature of the counterion and apolar solvent

\footnotetext{
* Corresponding author. Tel.: +39 091 6459844; fax: +39 091590015. E-mail address: turco@unipa.it (V.T. Liveri).
}

strongly influence the hosting capability of the micellar aggregates [1-4].

Further investigations on this subject have emphasized that few small-size hydrophilic molecules distributed among several reverse micelles do not cause significant changes of micellar structural and dynamic properties. On the other hand, marked changes on the size, shape and molecular organization of micellar aggregate can be expected when a big molecule or many small-size molecules are entrapped within the reverse micelle. In the latter case, the solubilization of finite amounts of amphiphilic substances leads to mixed aggregates of oriented solubilizate/surfactant molecules; while polar and ionic substances can form a separate internal hydrophilic core or a mixed cluster composed by the solute and the surfactant head groups [5,6].

Indeed, it has been found that the solubilization of increasing amounts of vitamin $\mathrm{E}$ in lecithin reverse micelles causes a progressive decrease of the micellar size and the formation of mixed vitamin E/lecithin aggregates while the addition of cyanamide determines an unidimensional growth of AOT and lecithin reverse micelles and the formation in the micellar core of a mixed cluster constituted by cyanamide molecules and surfactant head groups $[7,8]$.

It is worth to mention that the properties of molecules confined within reverse micelles are different from those of isolated 
molecules or in the pure bulk state and these properties can be opportunely modulated by changing some external parameters such as the solubilizate-to-surfactant molar ratio, temperature and nature of the system components [9].

Taking into account the steeply increasing theoretical and practical interest devoted to self-assembled nanostructures, the evaluation of the real potentialities of solutions of reverse micelles to produce and stabilize organized nanoclusters of hydrophilic substances could be of utmost importance to open the door to new and interesting technological applications of solute/surfactant/apolar solvent systems $[5,8]$.

Moreover, from a theoretical point of view, these systems are also interesting because they give the opportunity to study solubilization and structural arrangement of finite amounts of hydrophilic solid substances within the reverse micellar core or the surfactant head-group nanodomain, size and shape control of molecular clusters in confined space and adsorption effects on the cluster properties.

In order to extend our knowledge on this field and to better understand the molecular details responsible of the solubilization power of reverse micellar systems, in the present work it has been investigated the confinement of two model chiral molecules, D and L-dimethyl tartrate as a function of the solubilizate-to-surfactant molar ratio $(R)$. The study has been performed using as surfactant sodium bis(2-ethylhexyl) sulfosuccinate (AOT), and $\mathrm{CCl}_{4}$ as solvent.

The state of confined dimethyl tartrates has been investigated by FT-IR, vibrational circular dichroism (VCD) spectroscopies and polarimetry. It has been amply proved that FT-IR is well suited to gain information simultaneously on the environments of spatially separated moieties of both solubilizate and surfactant molecules and consequently on the structural arrangement of solubilizate containing reverse micelles. VCD is quite sensitive to conformational changes of chiral molecules, induced for example by different solvents. In the case of chiral molecules in direct micelles or vesicles VCD has been used for peptides [10] and proteins [11].

\section{Experimental}

(-)-(2S,3S)-Dimethyl tartrate (dimethyl-D-tartrate or DDT) and $(+)-(2 R, 3 R)$-dimethyl tartrate (dimethyl-L-tartrate or DLT) were Fluka products (optical purity $>99 \%$ ) and used without further purification. Sodium bis(2-ethylhexyl) sulfosuccinate (AOT, Sigma, $99 \%$, racemic mixture) was dried under vacuum for several days before use. To remove residual traces of water, solutions of AOT in $\mathrm{CCl}_{4}$ (Riedel-de Haën, 99.8\%) were gently stirred for several days in the presence of activated type 4A molecular sieves (Fluka, beads of $4 \AA ̊$ pore size). Solutions at various solubilizate-to-surfactant molar ratios $(R)$ were prepared by adding the appropriate amounts of $\mathrm{AOT} / \mathrm{CCl}_{4}$ solutions to a weighed quantity of DDT or DLT.

While $\mathrm{D}$ and L-dimethyl tartrate have low solubility in $\mathrm{CCl}_{4}$ $\left(0.040 \mathrm{M}\right.$ for both enantiomers at $\left.25^{\circ} \mathrm{C}\right)$, the highest $R$ value which can be reached in $0.158 \mathrm{M} \mathrm{AOT} / \mathrm{CCl}_{4}$ solutions in the presence of solubilizate crystals is $R=1.9$ for DDT and $R=1.4$ for DLT. This evidence of a different behavior of $\mathrm{D}$ and $\mathrm{L}$ enantiomers is somewhat at odds with all other findings of this work: in particular no difference has been seen by chiroptical techniques.

On the other hand, in absence of solubilizate crystals, dimethyl tartrates can be solubilized up to $R=4$ in $0.158 \mathrm{M} \mathrm{AOT} / \mathrm{CCl}_{4}$ solutions at $25^{\circ} \mathrm{C}$ giving samples sufficiently stable to allow their FT-IR and VCD investigation. This interesting supersaturation effect indicates that confinement of hydrophilic substances within reverse micelles effectively influences the homogeneous nucleation process inhibiting the crystal growth and precipitation of thermodynamically unstable samples.

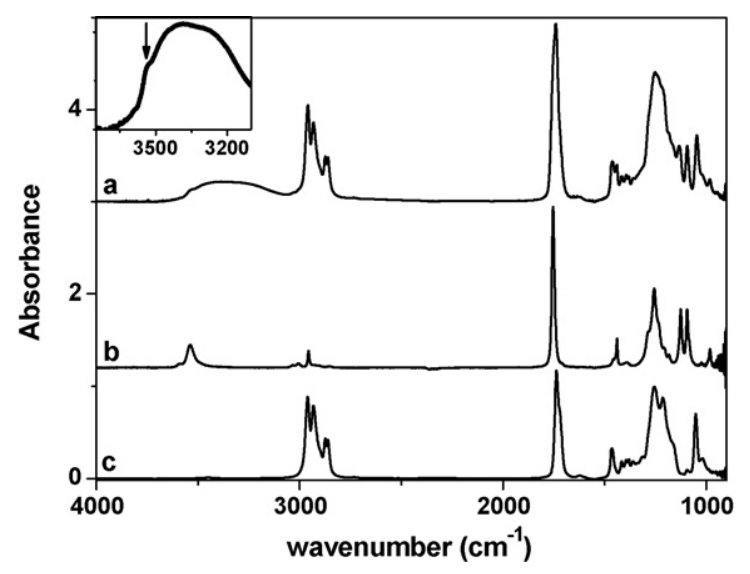

Fig. 1. Infrared spectra of (a) DDT/AOT $/ \mathrm{CCl}_{4}$ ([AOT] $=0.158 \mathrm{M}, R=1.0$; (b) $\mathrm{DDT} / \mathrm{CCl}_{4}$ $([\mathrm{DDT}]=0.04 \mathrm{M})$; (c) AOT $/ \mathrm{CCl}_{4}([\mathrm{AOT}]=0.158 \mathrm{M})$ systems in the $900-4000 \mathrm{~cm}^{-1}$ frequency range. The inset shows the enlarged $\mathrm{OH}$ band of DDT in $\mathrm{AOT} / \mathrm{CCl}_{4}$ solution.

FT-IR spectra of all liquid samples were recorded with solvent compensation in the spectral region $900-4000 \mathrm{~cm}^{-1}$ using a PerkinElmer (Spectrum BX) spectrometer and a cell with $\mathrm{CaF}_{2}$ windows. The FT-IR spectra of solid $\mathrm{D}$ and L-dimethyl tartrate were recorded using a pressed disk of the compound mixed with $\mathrm{KBr}$ powder. All measurements were collected at $25^{\circ} \mathrm{C}$ with a spectral resolution of $2 \mathrm{~cm}^{-1}$.

VCD spectra in the mid-IR region were taken in 0.05 and $0.2 \mathrm{~mm}$ path length $\mathrm{BaF}_{2}$ cells using a JASCO FVS4000 FTIR instrument equipped with an MCT detector; 4000 scans were taken, with $4 \mathrm{~cm}^{-1}$ resolution. The spectra were recorded for both enantiomers, and mirror image appearance was obtained for them.

Optical rotation measurements have been performed at $25^{\circ} \mathrm{C}$ on a JASCO P-1010 polarimeter at sodium D line and using a $1 \mathrm{dm}$ optical path cell.

\section{Results and discussion}

A typical spectrum of dimethyl-D-tartrate/AOT/CCl 4 system in the frequency range $900-4000 \mathrm{~cm}^{-1}$ is shown in Fig. 1. For comparison, the spectra of dimethyl-D-tartrate $/ \mathrm{CCl}_{4}$ and $\mathrm{AOT} / \mathrm{CCl}_{4}$ systems are also shown. All the observed bands can be attributed to the functional groups of dimethyl-D-tartrate (DDT) and AOT and their assignments, made according to the literature, are collected

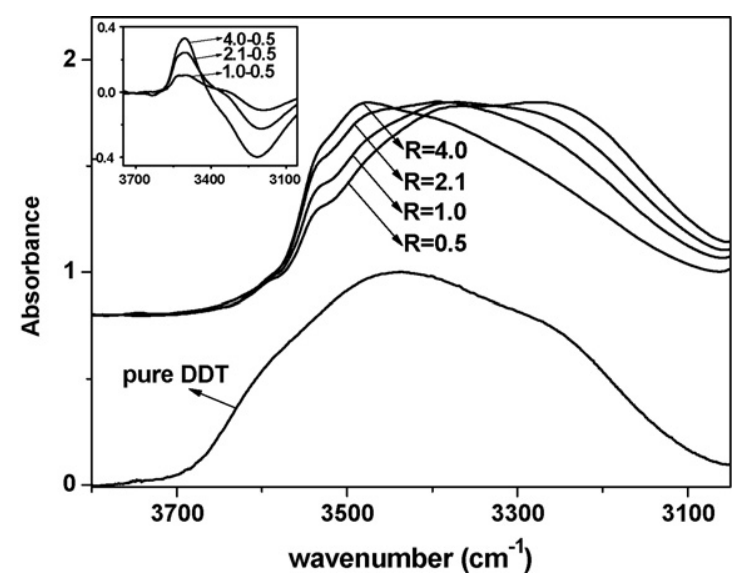

Fig. 2. Comparison between the normalized $\mathrm{OH}$ stretching bands of solid DDT and those of DDT/AOT/CCl $\mathrm{Cl}_{4}$ system at various $R$ values. The inset shows the difference spectra obtained by subtracting spectrum at $R=0.5$ to that of the other DDT/AOT/CCl samples. 
Table 1

Infrared frequencies of the functional groups of dimethyl-D-tartrate and AOT in the $1000-4000 \mathrm{~cm}^{-1}$ frequency range and their assignments

\begin{tabular}{|c|c|c|c|c|}
\hline DDT in $\mathrm{CCl}_{4}$ & Solid DDT & DDT in DDT/AOT/CCl 4 & $\mathrm{AOT}$ in DDT/AOT/CCl 4 & Assignment \\
\hline $3539,3592 \mathrm{sh}$ & $3600-3000$ & $3600-3000$ & & $\begin{array}{l}\nu(\mathrm{OH}) \text { intramolecularly H-bonded } \\
\nu(\mathrm{OH}) \text { intra and intermolecularly } \mathrm{H} \text {-bonded }\end{array}$ \\
\hline 3006 & & & $\begin{array}{l}2961 \\
2932\end{array}$ & $\begin{array}{l}v_{\text {as }}\left(\mathrm{CH}_{3}\right) \\
v_{\text {as }}\left(\mathrm{CH}_{2}\right)\end{array}$ \\
\hline 2956 & & & $\begin{array}{l}2874 \\
2861\end{array}$ & $\begin{array}{l}v\left(\mathrm{C}^{*} \mathrm{H}\right) \\
v_{\mathrm{s}}\left(\mathrm{CH}_{3}\right) \\
v_{\mathrm{s}}\left(\mathrm{CH}_{2}\right)\end{array}$ \\
\hline 1754 & 1748 & 1752 & $\begin{array}{l}1736 \\
1130-1310 \\
1050\end{array}$ & $\begin{array}{l}\nu(\mathrm{CO}) \\
v_{\mathrm{as}}\left(\mathrm{SO}_{3}^{-}\right)+\text {stretch of ester linkage } \\
v_{\mathrm{s}}\left(\mathrm{SO}_{3}^{-}\right)\end{array}$ \\
\hline
\end{tabular}

in Table 1 together with the band assignments of dimethyl-Dtartrate in the pure solid state [8,12]. Similar data concerning dimethyl-L-tartrate (DLT) have not been reported because they are indistinguishable from those of DDT.

From the spectra of Fig. 1 it can be seen that the DDT and AOT bands are more or less affected when both are present in the solution, unveiling direct interaction between DDT and reverse micelles. The most significant bands, which will be analyzed here in detail, are those due to the stretchings of $\mathrm{OH}, \mathrm{CO}$ and $\mathrm{SO}_{3}{ }^{-}$.

\subsection{OH stretching band}

It is noteworthy that dimethyl-D-tartrate in a dilute $\mathrm{CCl}_{4}$ solution, i.e., in the monomeric state, gives a sharp absorption at $3539 \mathrm{~cm}^{-1}$ with a shoulder at $3592 \mathrm{~cm}^{-1}$ assigned to the stretching vibrations of intramolecularly $\mathrm{H}$-bonded $\mathrm{OH}$ groups. In particular, these absorptions are due to the stretching vibration of $\mathrm{OH}$ groups that are hydrogen bonded to either $\mathrm{C}=\mathrm{O}$ or $\mathrm{O}-\mathrm{CH}_{3}$ groups attached to the vicinal chiral carbon $[12,13]$.

On the other hand, when dimethyl-D-tartrate is solubilized in $0.158 \mathrm{M} \mathrm{AOT} / \mathrm{CCl}_{4}$ solutions, the $\mathrm{OH}$ band appears broadened and red-shifted suggesting extensive intermolecular $\mathrm{H}$-bonding which, being unconstrained by intramolecular tensions and enhanced by cooperative effects, allows to establish stronger $\mathrm{H}$-bonds as well as to widen the spectrum of differently hydrogen bonded DDT populations [14]. This finding can be taken as a clear indication that DDT is entrapped in the polar domain of the AOT reverse micelles leading to strong DDT/DDT and DDT/AOT interactions. The same behavior has been observed by analyzing the spectra of DLT in $\mathrm{AOT} / \mathrm{CCl}_{4}$ solutions.

However, a closer inspection of the OH band of the confined DDT (see inset of Fig. 1) reveals the occurrence of a spectral feature at $3539 \mathrm{~cm}^{-1}$ which can be taken as a clue that part of DDT is dispersed as monomers in the bulk solvent. In order to estimate the fraction of these molecules, we have evaluated the area $\left(A_{\mathrm{f}}\right)$ of the $\mathrm{OH}$ contribution at $3539 \mathrm{~cm}^{-1}$ in terms of Gaussian component of the entire OH band. Then, the fraction of DDT or DLT monomers $\left(X_{\mathrm{f}}\right)$ dispersed in the bulk solvent was calculated by

$X_{\mathrm{f}}=\frac{0.02 A_{\mathrm{f}}}{0.158 R A_{\mathrm{m}}}$

where $A_{\mathrm{m}}$ is the area of the $\mathrm{OH}$ component at $3539 \mathrm{~cm}^{-1}$ of $0.02 \mathrm{M}$ DDT or DLT in $\mathrm{CCl}_{4}$ and $0.158 R$ is the overall molar concentration of the solubilizate. For all $R$ values and for both enantiomers we have found that $X_{\mathrm{f}} \approx 0.08$ indicating that only a small fraction of the chiral molecules are dispersed in the bulk solvent.

The $R$ dependence of the $\mathrm{OH}$ stretching bands of DDT dissolved in $\mathrm{AOT} / \mathrm{CCl}_{4}$ solutions, obtained by subtracting the spectrum
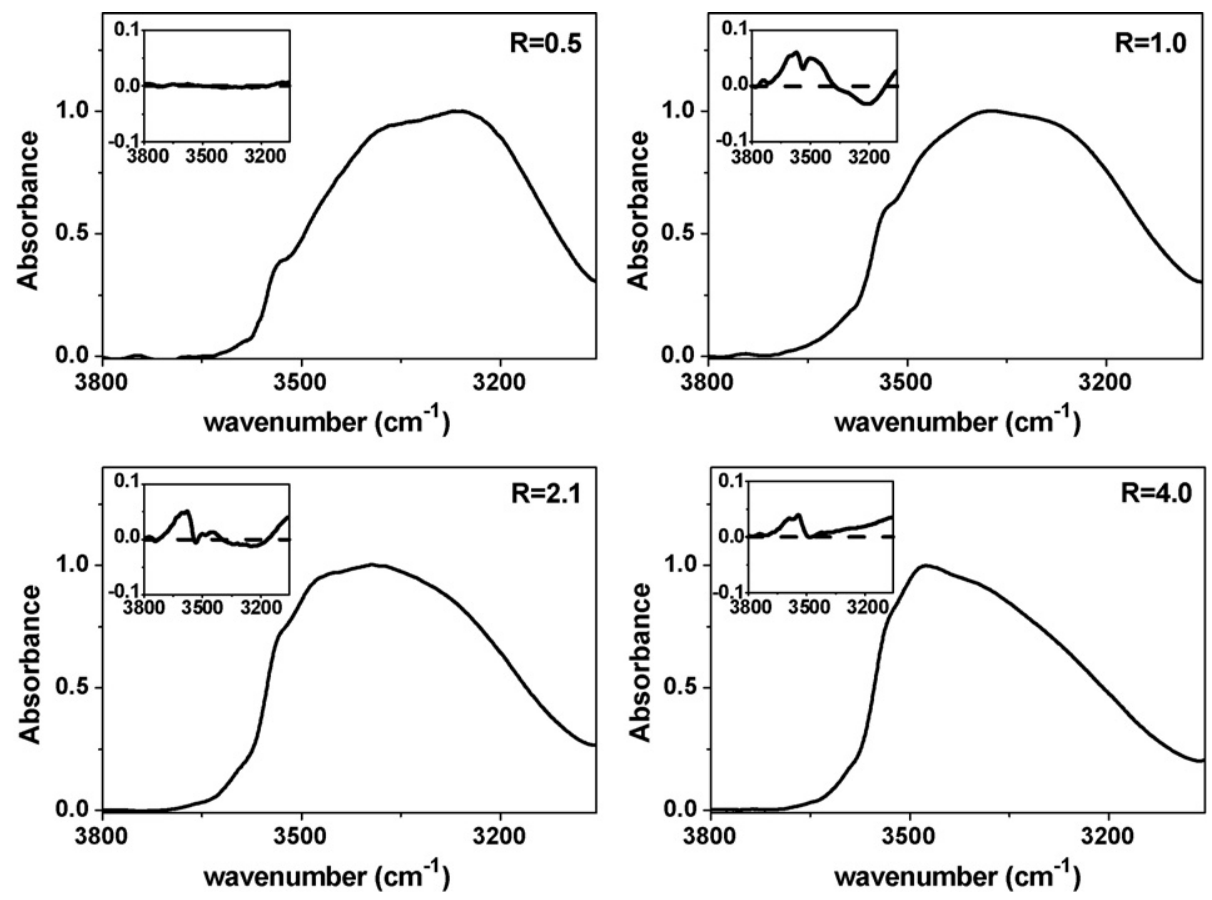

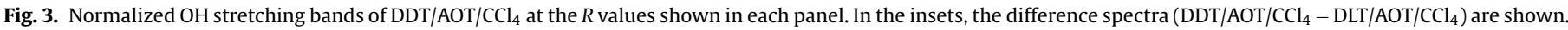




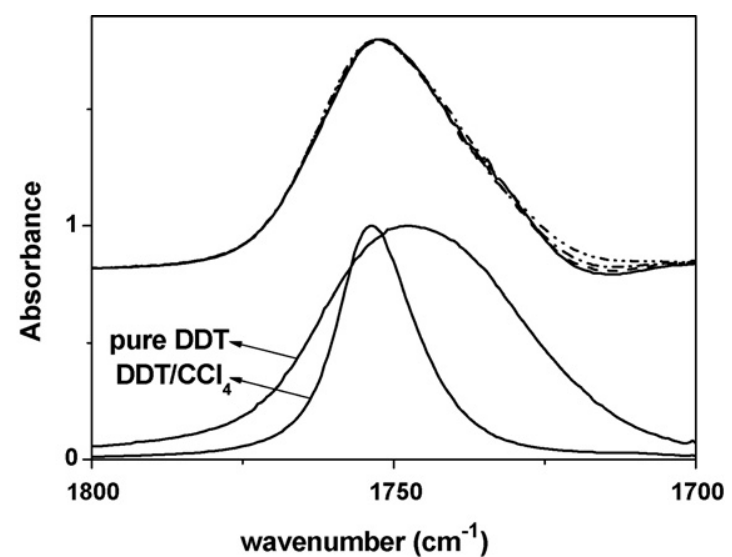

Fig. 4. Normalized CO stretching bands of solid DDT, DDT/CCl $([\mathrm{DDT}]=0.04 \mathrm{M})$ and $\mathrm{DDT} / \mathrm{AOT} / \mathrm{CCl}_{4}$ system at various $R$ values ([AOT] $=0.158 \mathrm{M} ; R=0.5$ solid line; $R=1.0$ dashed line; $R=2.1$ dashed-dotted line; $R=4.0$ dashed-dotted-dotted line).

of $\mathrm{AOT} / \mathrm{CCl}_{4}$ solution and normalized to the same height of the band maximum is shown in Fig. 2. For comparison, the spectra of dimethyl-D-tartrate in the pure solid state are also shown. It can be noted that the $\mathrm{OH}$ bands are progressively blue-shifted by increasing $R$ and that, notwithstanding this shift, appreciable spectral differences with respect to the band of pure DDT can be observed. This behavior can be rationalized by hypothesizing that the first DDT molecules are accommodated in the micellar head-group domain so that they form strong $\mathrm{H}$-bonds with the surrounding hydrophilic groups of AOT. Further addition of DDT molecules involves their location in less comfortable sites where DDT/AOT head groups and/or DDT/DDT interactions characterized by less strong intermolecular H-bonds are established. However, taking into account that the $\mathrm{OH}$ band of pure DDT is not approached even at the higher $R$ value, the formation of a well-defined internal core composed by DDT molecules can be ruled out. This picture is further circumstantiated by the difference spectra reported in the inset of Fig. 2 obtained by subtracting the normalized $\mathrm{OH}$ band at $R=0.5$ from those of DDT/AOT/CCl $/ \mathrm{Cl}_{4}$ samples at larger $R$ values. It can be noted that by increasing the $R$ value the contribution occurring at about $3500 \mathrm{~cm}^{-1}$ increases at the expenses of the contribution occurring at about $3200 \mathrm{~cm}^{-1}$. Similar conclusions can be drawn by analyzing the normalized $\mathrm{OH}$ stretching bands of DLT in $\mathrm{CCl}_{4}$, $\mathrm{AOT} / \mathrm{CCl}_{4}$ solutions and in the pure state.

In order to closely compare the $\mathrm{OH}$ stretching bands of DDT and DLT in AOT/CCl 4 solutions, we have reported in each panel of Fig. 3 the normalized bands of DDT at various $R$ values and in the insets the difference spectra (DDT/AOT/CCl $-\mathrm{DLT} / \mathrm{AOT} / \mathrm{CCl}_{4}$ ) at the same $R$ values. An inspection of the insets shows the occurrence of only very small and uncorrelated departures from zero which could be reasonably attributed to minute differences of the water traces present in each pair of enantiomers.

\section{2. $\mathrm{CO}$ stretching band of $\mathrm{D}$ and $\mathrm{L}$-dimethyl tartrate}

The DDT CO stretching bands, obtained by subtracting the spectrum of $\mathrm{AOT} / \mathrm{CCl}_{4}$ solution from those of DDT/AOT/CCl $/ \mathrm{Cl}_{4}$ samples and normalized to the same height of the $\mathrm{CO}$ band maximum, are shown in Fig. 4. For comparison, the normalized CO bands of DDT in $\mathrm{CCl}_{4}$ and in the pure solid state are also reported. Apart small differences occurring at about $1715 \mathrm{~cm}^{-1}$, it is noteworthy that, by increasing $R$, no significant variation of the band position and shape occurs. This implies that the environment probed by $\mathrm{CO}$ groups of DDT confined in the reverse micelles does not change significantly with $R$. On the other hand, the small spectral changes observed at about $1715 \mathrm{~cm}^{-1}$ can be reasonably attributed to minor perturbation of the environment of the CO group of the AOT $\beta$ chain induced by the presence of increasing amount of DDT in the reverse micelles $[15,16]$. Moreover, it can be noted that the frequency at the band maximum $\left(1752 \mathrm{~cm}^{-1}\right)$ and the width at half height $\left(28 \mathrm{~cm}^{-1}\right)$ of dimethyl-D-tartrate confined in AOT reverse micelles are intermediate between that in $\mathrm{CCl}_{4}\left(1754\right.$ and $\left.15 \mathrm{~cm}^{-1}\right)$ and in the pure solid state $\left(1748\right.$ and $\left.39 \mathrm{~cm}^{-1}\right)$. This finding emphasizes the peculiar state of DDT confined in reverse micelles confirming that the largest
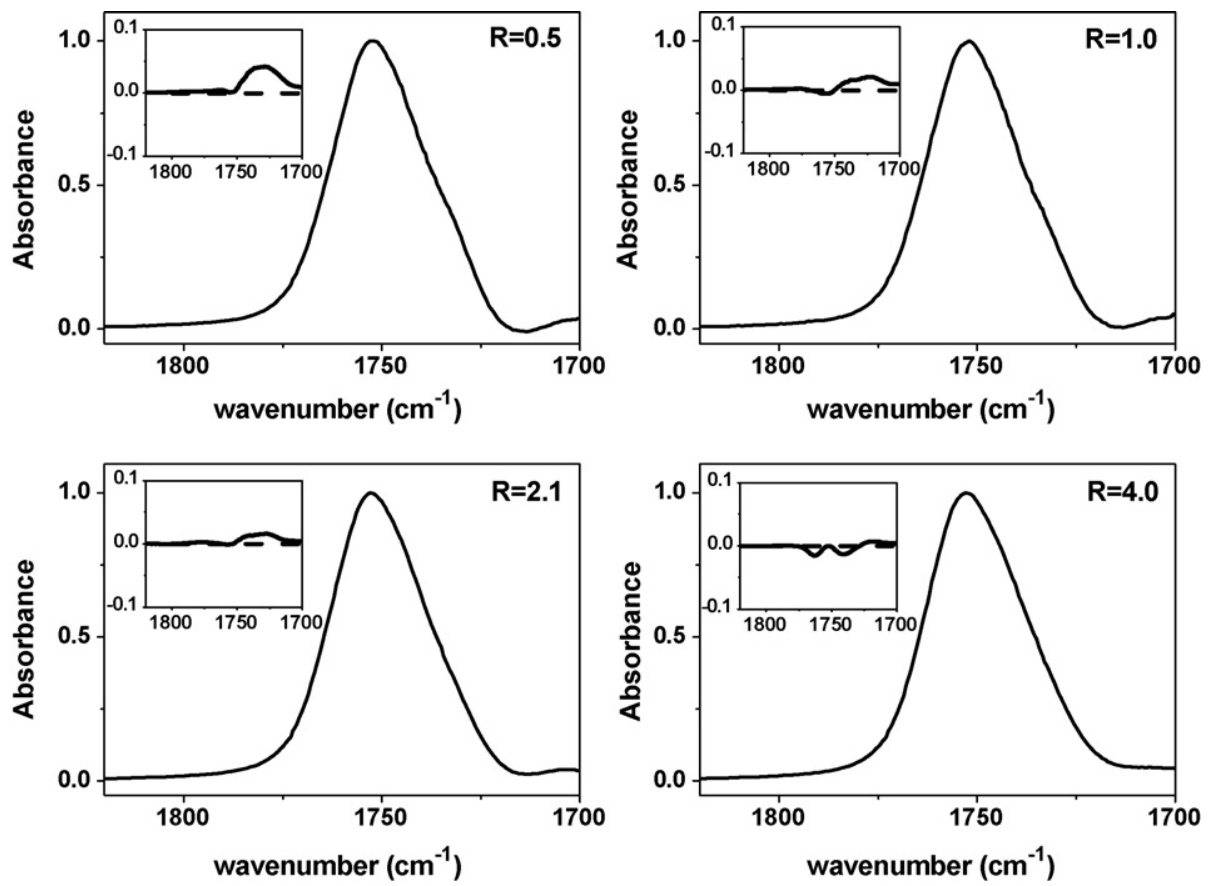

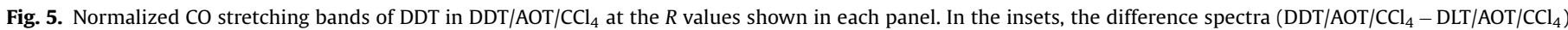
are shown. 


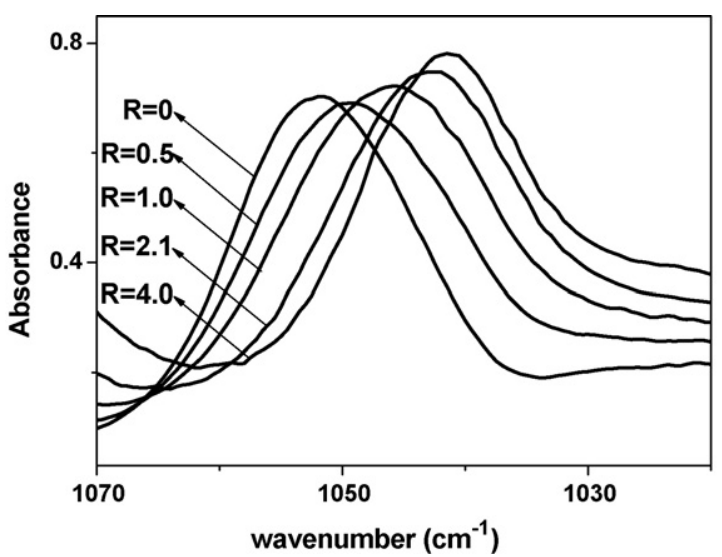

Fig. 6. AOT $\mathrm{SO}_{3}{ }^{-}$stretching bands in $\mathrm{DDT} / \mathrm{AOT} / \mathrm{CCl}_{4}$ system at various $R$ values.

amount of DDT is entrapped in the reverse micelles and that its $\mathrm{CO}$ groups are engaged in interactions with the $\mathrm{OH}$ groups of surrounding DDT molecules and/or with the hydrophilic head groups of AOT. The similar behavior has been observed by analyzing the $\mathrm{CO}$ stretching band of DLT in $\mathrm{AOT} / \mathrm{CCl}_{4}$ solutions. Moreover, as it is shown in the insets of Fig. 5, apart minor changes observed at about $1715 \mathrm{~cm}^{-1}$ no significant difference between the CO band of the two enantiomers has been detected implying that the CO groups of both compounds experience the same local environment.

\section{3. $\mathrm{AOT} \mathrm{SO}_{3}{ }^{-}$stretching band}

The band maxima of the $\mathrm{AOT} \mathrm{SO}_{3}{ }^{-}$symmetric stretching absorption in DDT/AOT/ $\mathrm{CCl}_{4}$ samples display a progressive shift to lower frequency as $R$ increases together with an intensity enhancement only at the higher $R$ values (see Fig. 6). The observed trend indicates a progressive increase of the fraction of $\mathrm{AOT} \mathrm{SO}_{3}{ }^{-}$groups

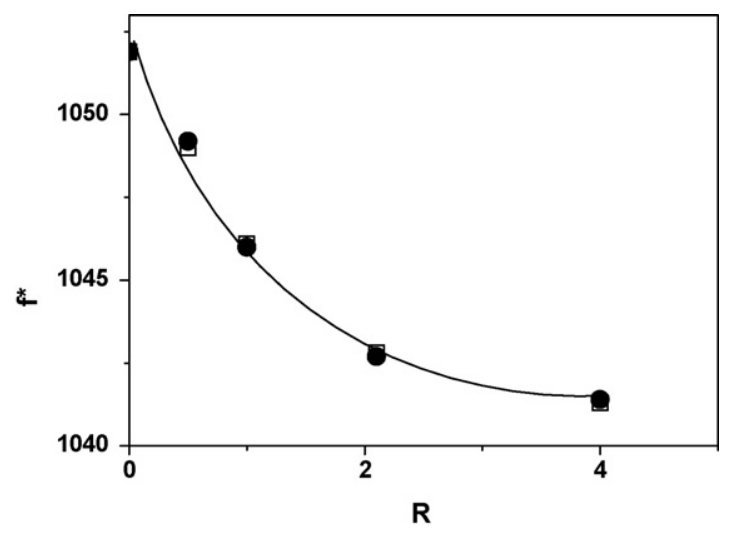

Fig. 8. $f^{*}$ values of the AOT $\mathrm{SO}_{3}{ }^{-}$head-group stretching band for the DDT/AOT/CCl $(\bullet)$ and DLT/AOT/CCl $/(\square)$ systems as a function of $R$.

engaged in tartrate-surfactant head-group interactions whereas the behavior of the band intensity reveals that these interactions do not affect significantly the dipole moment of the $\mathrm{SO}_{3}{ }^{-}$oscillators, except for the supersaturated samples. Moreover, as it is shown in the insets of Fig. 7, no significant difference between the normalized AOT $\mathrm{SO}_{3}{ }^{-}$bands of samples containing the two enantiomers at the same $R$ is observed, implying that the AOT $\mathrm{SO}_{3}{ }^{-}$group does not distinguish between the enantiomer type. The dependence of the frequency $\left(f^{*}\right)$ at the band maximum with $R$ for both solubilizates is depicted in Fig. 8. It can be noted that, after an initial rapid decrease, the $f^{*}$ value trends to a plateau. This behavior is similar to that shown by cyanamide when it is confined within AOT reverse micelles and similarly it makes possible to state that solubilizate/surfactant interactions mainly occur between the $\mathrm{OH}$ group of DDT or DLT and the $\mathrm{SO}_{3}{ }^{-}$surfactant ionic head groups tending to the complete saturation at the higher $R$ $[8,17]$.
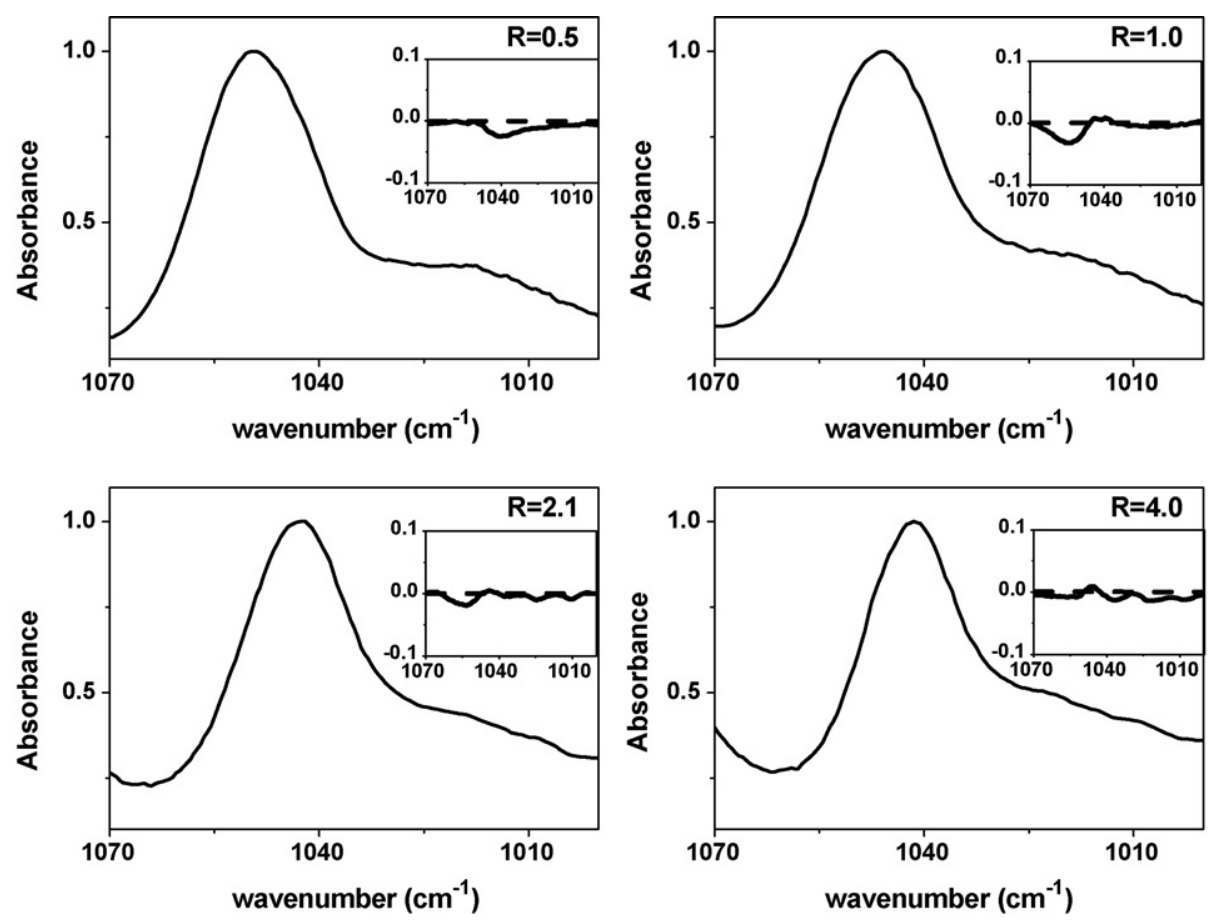

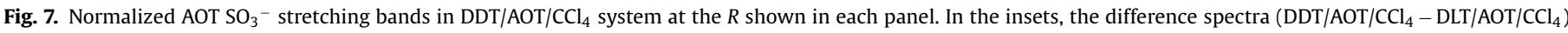
are shown. 


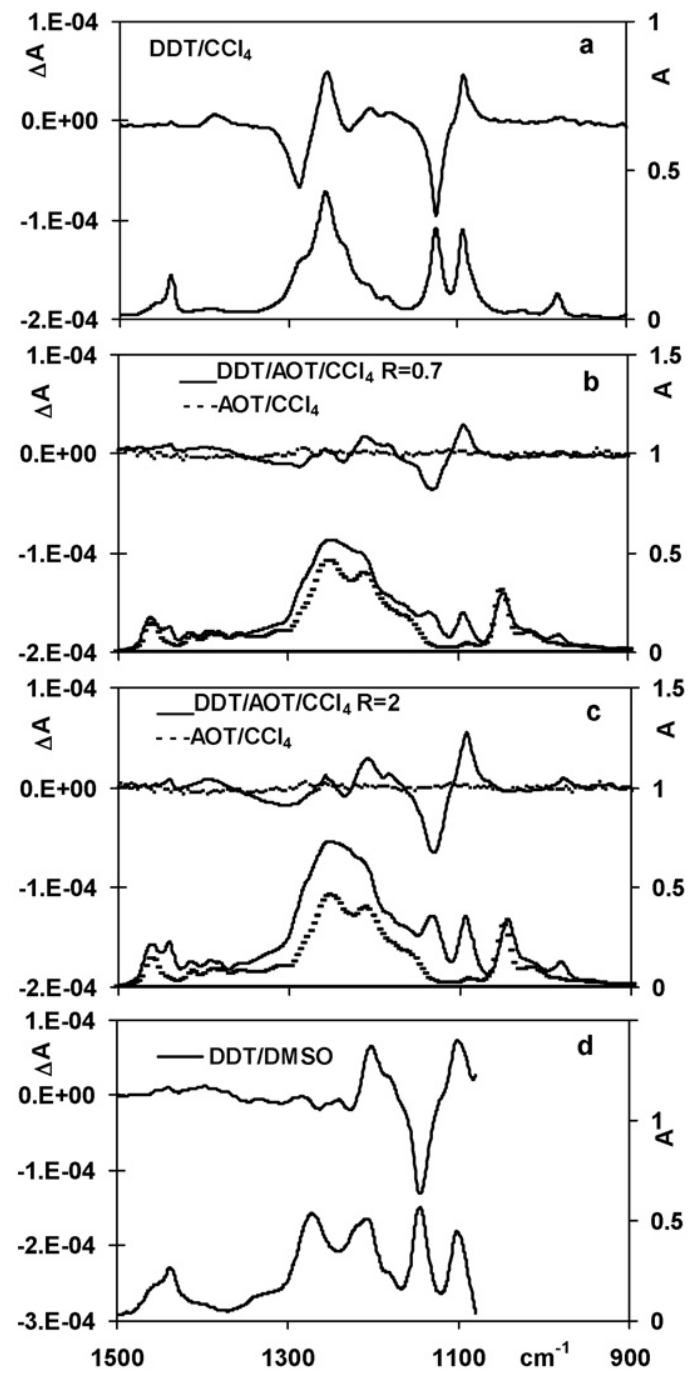

Fig. 9. VCD and absorption spectra of (a) $\mathrm{DDT} / \mathrm{CCl}_{4}[0.04 \mathrm{M}] 200 \mu \mathrm{m}$ cell; (b) $\mathrm{DDT} / \mathrm{AOT} / \mathrm{CCl}_{4}([\mathrm{AOT}]=0.158 \mathrm{M}, R=0.7) 50 \mu \mathrm{m}$ cell compared to $\mathrm{AOT} / \mathrm{CCl}_{4}$; (c) $\mathrm{DDT} / \mathrm{AOT} / \mathrm{CCl}_{4}([\mathrm{AOT}]=0.158 \mathrm{M}, R=2) 50 \mu \mathrm{m}$ cell, compared to $\mathrm{AOT} / \mathrm{CCl}_{4}$; (d) DDT/DMSO [0.41 M] $50 \mu \mathrm{m}$ cell.

\section{4. $1050-1300 \mathrm{~cm}^{-1}$ VCD signals of dimethyl-D-tartrate}

As already reported in the literature [12,18], two strong positive VCD couplets (the positive components of positive doublets being at lower wavenumbers than the negative ones) are observed in $\mathrm{CCl}_{4}$ solutions, the first one at $1095-1126 \mathrm{~cm}^{-1}$ in correspondence with two absorption peaks, the second at $1257-1290 \mathrm{~cm}^{-1}$ in correspondence with a large structured absorption peak, centred at $1257 \mathrm{~cm}^{-1}$. If we consider the spectra of DDT in AOT/CCl (Fig. 9), we see that the first couplet is not much perturbed both in absorption and VCD spectra with just a blue shift of the higher frequency component of about $10 \mathrm{~cm}^{-1}$. The second VCD couplet instead changes quite dramatically. This fact can be appreciated already from absorption data, especially considering the difference spectra with respect to AOT, where the two shoulders observed on the two sides of the peak at $1257 \mathrm{~cm}^{-1}$ in $\mathrm{CCl}_{4}$ solutions increase in intensity in AOT micelles (Fig. 9b and c).

Considering VCD, in correspondence with the couplet obtained in $\mathrm{CCl}_{4}$, one observes a broadened negative feature at about $1300 \mathrm{~cm}^{-1}$ and a positive band at $1212 \mathrm{~cm}^{-1}$. A detailed normal mode analysis is quite a hard task since it should take into account

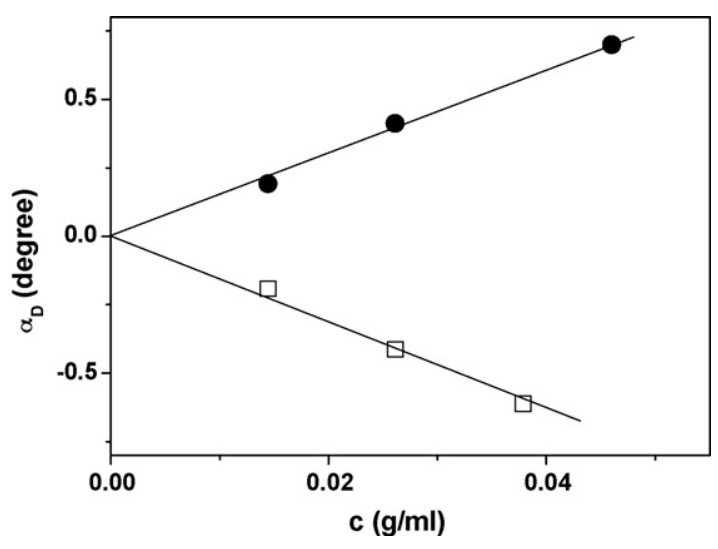

Fig. 10. Observed optical rotation $\left(\alpha_{\mathrm{D}}\right)$ at sodium $\mathrm{D}$ line of DDT/AOT/CCl 4 $\left([\mathrm{AOT}]=0.158 \mathrm{M}(\bullet)\right.$ and DLT $/ \mathrm{AOT} / \mathrm{CCl}_{4}([\mathrm{AOT}]=0.158 \mathrm{M}(\square)$ as a function of dimethyl tartrate concentration (c) measured in a $1 \mathrm{dm}$ cell.

quite a few conformations: nine of these had been considered by Buffeteau et al. [12] and give a good prediction of the IR and VCD spectra of dimethyl tartrate (in their case DLT) in $\mathrm{CCl}_{4}$, where one single conformation, among the nine examined, is found to be populated $70 \%$, and thus it grossly accounts for the observed bands. The normal modes originating the first couplet commented here are due to $\mathrm{C}-\mathrm{O}$ stretchings of the two $\mathrm{HC}^{*} \mathrm{OH}$ groups plus little contributions from deformation modes of $\mathrm{C}^{*} \mathrm{H}$ and $\mathrm{OH}$. The higher frequency band of the second couplet is due to bending of $\mathrm{C}^{*} \mathrm{H}$ and $\mathrm{OH}$ of the two $\mathrm{HC}^{*} \mathrm{OH}$ groups, the lower frequency one is quite delocalised and is due to $\mathrm{C}-\mathrm{C} / \mathrm{C}-\mathrm{O}$ stretchings of the $\mathrm{COOCH}_{3}$ groups plus deformations of $\mathrm{C}^{*} \mathrm{H}$ and $\mathrm{OH}$ of the two central groups $\mathrm{HC}^{*} \mathrm{OH}$. To mimic all possible geometries of DDT in interaction with AOT is beyond the scope of this work. However it has already been reported in the literature [18] that the couplet at $1257-1290 \mathrm{~cm}^{-1}$, observed also in $\mathrm{CDCl}_{3}$, changes in case of DMSO solutions, while the lower frequency couplet is less affected by changing the solvent. For sake of comparison we report our own spectra recorded in DMSO. The band at $1126 \mathrm{~cm}^{-1}$ of the first couplet is blue shifted by 20 wavenumbers changing from $\mathrm{CCl}_{4}$ to DMSO and the couplet at $1250-1300 \mathrm{~cm}^{-1}$ is nearly lost, while a band at $1204 \mathrm{~cm}^{-1}$ is recorded. We conclude that VCD spectral data suggest that in presence of AOT and DMSO the hydroxyls are strongly perturbed: we infer that both the $\mathrm{SO}_{3}{ }^{-}$group in AOT and the SO group in DMSO break intramolecular H-bonds and give rise to intermolecular $\mathrm{H}$-bonds, as suggested also from the $\mathrm{OH}$ stretching spectroscopic region previously commented on. This fact inevitably changes the $\mathrm{OH}$ orientation of DDT, thus particularly affecting the bands originated by their deformation modes, and possibly influences the population of conformers and even their type, due to the diminished presence of stabilizing intramolecular H-bonds.

\subsection{Optical rotation of dimethyl-tartrates in AOT reverse micelles}

The observed optical rotation $\left(\alpha_{\mathrm{D}}\right)$ at sodium $\mathrm{D}$ line of $\mathrm{DDT} / \mathrm{AOT} / \mathrm{CCl}_{4}$ and $\mathrm{DLT} / \mathrm{AOT} / \mathrm{CCl}_{4}$ solutions as a function of dimethyl tartrate concentration (c) is shown in Fig. 10. The linear trends indicate that effects due to dimethyl tartrate concentration are negligible. Thus, by least square analysis of these experimental data, the specific rotation values of DDT $\left(+15.2 \pm 0.4 \mathrm{deg} \mathrm{mlg}^{-1} \mathrm{dm}^{-1}\right)$ and DLT $\left(-15.8 \pm 0.6 \mathrm{deg} \mathrm{mlg} \mathrm{m}^{-1} \mathrm{dm}^{-1}\right)$ were calculated. Apart the sign, it is worth to note the concordance of these quantities within the experimental errors, confirming that the AOT reverse micelles do not discriminate the two enantiomers. 
Moreover, since the specific rotation $\left(\left[\alpha_{D}\right]\right)$ of chiral compound in different media is influenced by the dielectric constant of the solvent and reflects solvent-induced effects on its preferential conformation(s), it is of interest to compare the $\left[\alpha_{D}\right]$ value of DDT in AOT reverse micelles $\left(+15.2 \mathrm{deg} \mathrm{mlg}^{-1} \mathrm{dm}^{-1}\right)$ with that in some conventional solvents such as $\mathrm{CCl}_{4}\left(+43.0 \mathrm{deg} \mathrm{ml} \mathrm{g}^{-1} \mathrm{dm}^{-1}\right)$, DMSO $\left(-3.1 \mathrm{deg} \mathrm{ml} \mathrm{g} \mathrm{m}^{-1}\right)$ and water $\left(-20.8 \mathrm{deg} \mathrm{ml} \mathrm{g} \mathrm{dm}^{-1}\right)[19,20]$. From the comparison of these values and according to literature, it can be argued that the polarity probed by DDT in the micellar environment is intermediate between that in $\mathrm{CCl}_{4}$ and DMSO [21]. Further contributions could arise from specific effects on the dimethyl tartrate conformations due to its confinement in the AOT reverse micelles.

\section{Conclusions}

Through a FT-IR investigation, detailed information on the state of D and L-dimethyl tartrate confined within dry sodium bis(2ethylhexyl) sulfosuccinate (AOT) reverse micelles dispersed in $\mathrm{CCl}_{4}$ has been obtained. The analysis of the spectral features of the most significant IR active groups $\left(\mathrm{OH}, \mathrm{CO}\right.$ and $\left.\mathrm{SO}_{3}{ }^{-}\right)$allows to hypothesize that both enantiomers are mainly confined in the reverse micelles and located in proximity to the surfactant head-group region. Also VCD spectroscopy is here demonstrated to be highly sensitive to the interactions of the chiral molecules with solvent or with surfactant agents, revealing very evident modifications of the signals and confirming the hypothesis of interactions of dimethyl tartrate with polar head of AOT.

The entrapment of dimethyl tartrates within reverse micelles involves marked changes of the typical H-bonding of dimethyl tartrate in the pure solid state and as monomers attributable to the establishment of system-specific solubilizate/surfactant headgroup interactions and confinement effects. Experimental data allow also to rule out the formation of a well-defined internal core formed by the chiral molecules even at the higher $R$ investigated including supersaturated samples. By an accurate comparison of the spectral behavior of the two enantiomers, the occurrence of significant differences in these interactions has been excluded, leaving without a direct experimental evidence able to explain their different solubility in AOT micellar solution. Unless one wants to speculate about minute energy differences between the two enantiomers [22], one needs to consider the possibility of different amounts of water or chiral contaminant traces in the micellar solutions and/or recognition of a single AOT configuration.

\section{Acknowledgment}

Financial support from the Università di Palermo and Brescia and PRIN 2006 is gratefully acknowledged.

\section{References}

[1] Z.J. Yu, R.D. Neuman, J. Am. Chem. Soc. 116 (1994) 4075-4076.

[2] F. Mantegazza, V. Degiorgio, M.E. Giardini, A.L. Price, D.C. Steytler, B.H. Robinson, Langmuir 14 (1998) 1-7.

[3] A. D’Aprano, I.D. Donato, F. Pinio, V. Turco Liveri, J. Solution Chem. 18 (1989) 949-955.

[4] J.J. Silber, A. Biasutti, E. Abuin, E. Lissi, Adv. Colloid Interface Sci. 82 (1999) 189-252.

[5] P. Calandra, C. Giordano, A. Ruggirello, V. Turco Liveri, J. Colloid Interface Sci. 277 (2004) 206-214.

[6] S. Abbate, T. Caronna, A. Longo, A. Ruggirello, V. Turco Liveri, J. Phys. Chem. B 111 (2007) 4089-4097.

[7] D. Bongiorno, L. Ceraulo, M. Ferrugia, F. Filizzola, A. Longo, A. Mele, A. Ruggirello, V. Turco Liveri, Int. J. Pharm. 312 (2006) 96-104.

[8] P. Calandra, A. Longo, A. Ruggirello, V. Turco Liveri, J. Phys. Chem. B 108 (2004) 8260-8268.

[9] V.Turco Liveri, in: M. Rosoff(Ed.), Nano-Surface Chemistry, Marcel Dekker, New York, 2001, pp. 473-504.

[10] C. Zhao, P.L. Polavarapu, Biopolymers 62 (2001) 336-340.

[11] Q. Xu, T.A. Keiderling, Protein Sci. 13 (2004) 2949-2959.

[12] T. Buffeteau, L. Ducasse, A. Brizard, I. Huc, R. Oda, J. Phys. Chem. A 108 (2004) 4080-4086.

[13] D.M.P. Gigante, F. Long, L.A. Bodack, J.M. Evans, J. Kallmerten, L.A. Nafie, T.B. Freedman, J. Phys. Chem. A 103 (1999) 1523-1537.

[14] T.B. Adler, N. Borho, M. Reiher, M.A. Suhm, Angew. Chem. Int. Ed. 45 (2006) 3440-3445.

[15] Y. Nagasoe, N. Ichiyanagi, H. Okabayashi, S. Nave, J. Eastoe, C.J. O’Connor, PCCP 1 (1999) 4395-4407.

[16] P.D. Moran, G.A. Bowmaker, R.P. Cooney, J.R. Bartlett, J.L. Woolfrey, Langmuir 11 (1995) 738-743.

[17] D.J. Christopher, J. Yarwood, P.S. Belton, B.H. Hills, J. Colloid Interface Sci. 152 (1992) 465-472.

[18] P.L. Polavarapu, C.S. Ewig, T. Chandramouly, J. Am. Chem. Soc. 109 (1987) 7382-7386.

[19] P. Zhang, P.L. Polavarapu, J. Phys. Chem. A 111 (5) (2007) 858-871.

[20] P.L. Polavarapu, A.G. Petrovic, P. Zhang, Chirality 18 (2006) 723-732.

[21] A. Ruggirello, V. Turco Liveri, Chem. Phys. 288 (2003) 187-195.

[22] M. Shinitzky, F. Nudelman, Y. Barda, R. Haimovitz, E. Chen, D.W. Deamer, Origins Life Evol. B. 32 (2002) 285-297. 